\section{Textile Testing}

Physical, Chemical and Microscopical. By Prof. John H. Skinkle. Pp. $x+272$. (London : Macmillan and Co., Ltd., 1940.) 15s. net.

PROF. SKINKLE'S book will be welcomed by those engaged in the textile industry as well as by teachers of textile technology. The author has had an ambitious aim. He has endeavoured to cover the physical, chemical and microseopical aspects of textile testing. The microscopical section, which deals with the identification of fibres, might with advantage have been illustrated. The physical section describes all the usual physical tests and, indeed, includes several tests which might not normally be expected in a book of this kind. In the chemical section, the author indicates how fibres, both synthetic and natural, may be related in chemical nature to the carbohydrates and proteins respectively, and he has given standard American methods of analysis of synthetic and natural carbohydrate fibres, and of wool and silk.

While the book in many respects may be regarded as a students' working manual, in others it is more ambitious. It outlines, for example, current conceptions of cellulose, wool and silk structure, and it makes abundant reference to the Journal of the Textile Institute, in which much modern textile research is published. The book should certainly make a valuable addition to the textile libraries of Great Britain. It is a pity that the diagrams, as, for example, that of the Soxhlet extraction apparatus on p. 159, are frequently poorly reproduced. In any later edition, attention should be given to this point.

\section{Plant Microtechnique}

By Donald Alexander Johansen. (McGraw-Hill Publications in the Botanical Sciences.) Pp. xi+ 523. (New York and London: McGraw-Hill Book Co., Inc., 1940.) 30s.

$\mathrm{T}$ HE author points out that during the past ten years immense strides have been made in microscopical technique and in our knowledge of lifehistories, and the present volume is an attempt to sift the mass of information in the literature and to correlate it so as to be of optimum service to laboratory workers. The book is not intended to be an encyclopædia of methods, but succeeds in giving in a readable form full details of a range of procedures which have been selected as the more reliable and generally useful, as the result of tests carried out in the Stanford laboratories. One of the marked features of modern methods is the tendency to use, wherever possible, whole-mount preparations, maceration and smear methods, and thicker in preference to thinner sections; and such points as these receive full attention. Adequate details are given for the making up of the stains recommended, and many useful hints are included as to the optimum thickness of section, time of day for collecting material for special purposes, etc., which may save much time in preliminarv tests. Though the author deals to some extent with reagents of American origin. this is not likely to interfere appreciably with the value of the book to users in Great Britain.

The first section of the book gives a general survey of methods of fixation, staining, microtoming and of more specialized techniques used in cytology, whilst the second and larger section shows how these may be adapted as special methods for the various phyla. It is in dealing with Algæ, Fungi and such lower types, where the constructional substances may differ so widely, that the greatest difficulties are encountered in selecting suitable methods of preservation and examination, and it is probably on such points as these that the book will prove of the greatest value as a reference work, especially as the bibliography may also be used if further details are required.

For each phylum some details are given of the life-cycle, suggestions as to methods of collecting, preservation as herbarium specimens or for laboratory purposes, cultural methods and suitable stains. These details apply not only to the more elementary class types such as Spirogyra, Vaucheria, etc., but also so far as possible to such less-exploited types as the Pyrrophyta, Cyanophyta, Fungi Imperfecti, Lichens, etc. In the higher phyla details of staining, thickness of sections for embryo sacs of Gymnosperms and Angiosperms, methods for germinating pollen grains, etc., also include very numerous hints which should prove of the greatest value.

\section{Industrial Solvents}

By Ibert Mellan. Pp. xi+480. (New York: Reinhold Publishing Corporation; London: Chapman and Hall, Ltd., 1939.) 66s. net.

$\mathrm{T}$ HIS is a mine of information; in it may be found the fungicidal action of diacetin, the intensity of the smell of isobutyl mercaptan, the solubility of nitrocellulose in ternary mixtures, and a vast amount of miscellaneous data which it would be exceedingly difficult to locate in the literature. Even in the book itself, the path is not always clear; a table of dielectric constants appears in the middle of a chapter on volatility and toxicity, while other tables and graphs having little or no connexion with the text crop up at intervals. The effect on the reader is the creation of a sense of bewilderment, particularly in the opening chapters, but this is dissipated by the major portion of the work, which is devoted to an excellent account of the properties of some 180 solvents arranged according to their chemical composition. Several pages are allotted to the more important substances and a few lines only to others, but it would seem that very little information has escaped the eye of the author, particularly when solutions of cellulose derivatives are concerned.

After a useful chapter on plasticizers, the book concludes somewhat unexpectedly with a section on graphical expression and interpretation which is so good that the intrusion may be forgiven.

Future editions would be improved by some rearrangement and a more detailed index, but even as it stands, the volume will be found indispensable to every user of solvents.
H. E. W. 